\title{
Konjenital Nazolakrimal Kanal Tıkanıklığının Doğum Şekliyle İlişkisi
}

\author{
The Relationship Between Congenital Nasolacrimal Duct \\ Obstruction and Mode of Delivery
}

Esra DAĞ ŞEKER, İnci Elif ERBAHÇECI TIMUR

Ankara Şehir Hastanesi, Göz Hastalıkları Kliniği, Ankara, Türkiye

\section{öz}

Amaç: Konjenital nazolakrimal kanal tıkanıklığı (KNLKT) görülme insidansı ile doğum şekli arasındaki ilişkiyi incelemektir. Gereç ve Yöntemler: Çalışmaya 2014-2017 yılları arasında epifora şikayetiyle başvuran KNLKT tanısı alan hastalar dahil edildi. Hastaların demografik ve klinik özellikleri belirlendi ve hastalar doğum şekline göre sezaryen doğum (SD) veya normal vajinal yolla doğum (NVD) olarak iki gruba ayrıldı. KNLKT görülme sıklığı, cinsiyet ve lateralite özellikleri gruplar arasında karşılaştırıldı.

Bulgular: Çalışmaya başvuru yaşı ortalama $5.5 \pm 4.6$ ay olan 62 hastanın 75 gözü dahil edildi. Çalışmaya dahil edilen hastaların doğum şekli \%59.7'sinde NVD iken \%40.3'ünde sezaryendi doğumdu. Hastaneye başvuru yaşı ve lateralite açııından gruplar arasında istatistiksel olarak anlamlı fark bulunmamaktaydı ( $p=0.501$ ve $p=0.624)$. Doğum şeklinin NVD ya da SD olması ile KNLKT görülme sıklığı arasında farklılık yoktu ( $p=0.128)$.

Sonuç: Çalışmamızda doğum şekli ile KNLKT görülme sıklığı arasında farklılık tespit edilmemiştir ancak sezaryen doğumun KNLKT için artmış bir risk faktörü olarak etyopatogenezdeki rolü literatürde tartışmalı olarak devam etmektedir.

Anahtar Sözcükler: Doğum şekli, Epifora, Konjenital nazolakrimal kanal tıkanıklığı, Konjenital dakriyostenoz

\section{ABSTRACT}

Objective: To investigate relationship between incidence of congenital nasolacrimal duct obstruction (CNLDO) and mode of delivery.

Material and Methods: Patients with epiphora, diagnosed as CNLDO in 2014-2017 years were enrolled the study. Demographic and clinical properties of the patients were identified and patients were divided into two groups according to mode of delivery, as cesarean section delivery (CSD) and normal vaginal delivery (NVD). Frequency of CNLDO, gender and laterality were compared between groups.

Results: Seventy five eyes of sixty two patients with mean age $5.5 \pm 4.6$ months were included in the study. Of the patients included in the study; mode of delivery was NVD in 59.7\% of the patients and CSD in $40.3 \%$ of the patients. There was no statistically significant difference between two groups according to age and laterality $(p=0.501$ and $p=$ 0.624). There was no difference between mode of delivery (CSD or NVD) and incidence of CNLDO ( $p=0.128)$.

Conclusion: There was no difference between mode of delivery and frequency of CNLDO in our study, however the role of CSD in the etiopathogenesis of CNLDO is still controversial according to the literature.

Key Words: Mode of delivery, Epiphora, Congenital nasolacrimal duct obstruction, Congenital dacryostenosis

(1) 0000-0001-6230-5529: DAĞ ŞEKERE 0000-0001-6514-3748: ERBAHÇECI TIMUR IE
Çıkar Çatışması / Conflict of Interest: Tüm yazarlar adına, ilgili yazar çıkar çatışması olmadığını belirtir

Etik Kurul Onayı / Ethics Committee Approval: Çalıșma için Ankara Şehir Hastanesi 1 Nolu Klinik Araştırmalar Etik Kurulu'ndan E1-21-2042/22.09.2021 numaralı onay alındı ve çalışma Helsinki Deklarasyonu prensiplerine uygun olarak yapıldı.

Yazarların katkısı / Contribution of the Authors: DAĞ ŞEKER E: Araştırma ve/veya makalenin hipotezini veya fikrini oluşturan, Sonuçlara ulașmak için planlama/metodoloji belirleme, Araștırma/çalıșmanın sorumluluğunu üstlenmek, ilerlemenin seyrini denetlemek, Hasta takibinde sorumluluk almak, ilgili biyolojik malzemelerin toplanması, veri yönetimi ve raporlama, deneylerin yürütülmesi, Sonuçların mantıksal olarak Yorumlanması ve sonuçlandırıması, Çalıșma için gerekli literatür taramasında sorumluluk almak, Çalıșmanın bütününün veya önemli bölümlerinin yazımında sorumluluk almak, Yazım ve dilbilgisi dıșında bilimse olarak gönderilmeden önce makaleyi gözden geçirme. ERBAHÇEC TiMUR iE: Sonuçara ulașmak için planlama/metodoloji belirleme, Araștrma/çalısman con deneylerin yürütülmesi, Sonuçların mantıksal ol bütününün veya önemli bölümlerinin yazımında sorumluluk almak, Yazım ve dilbilgisi dışında bilimsel olarak gönderilmeden önce makaleyi gözden geçirme.

Atıf yazım șekli / How to cite : Dağ Şeker E ve Erbahçeci Timur IE. Konjenital Nazolakrimal Kanal Tıkanıkığının Doğum Şekliyle Ilișkisi . Türkiye Çocuk Hast Derg 2022;16:385-388.
Yazışma Adresi / Correspondence Address:

\section{Esra DAĞ SEEKER}

Ankara Şehir Hastanesi, Göz Hastalıkları Kliniği, Ankara, Türkiye

E-posta: dr.esra.seker@gmail.com
Geliș tarihi/ Received : : 16.09.2022 Kabul tarihi / Accepted : 09.12.2022 Elektronik yayın tarihi $\quad$ : 24.02.2022 Online published

DOI: 10.12956/tchd.996648 


\section{GiRiş}

Konjenital nazolakrimal kanal tıkanıklığı (KNLKT), yaşamın ilk yılındaki epiforanın en sık sebebidir (1). İnsidansı \%11 ile \%20 arasında bildirilmiştir (1-3).

Genellikle yaşamın ilk haftalarından sonra, tek ya da iki taraflı olarak, sulanma, kapak kenarlarında mukoid sekresyon birikmesi, kirpiklerde ıslanma ile başlayıp, staza sekonder enfeksiyon eklenmesiyle sekresyonun mukopurülan karakter kazanması ve tekrarlayıcı konjonktivit tablosuyla prezente olmakta, persistan vakalar dakriyosistit, preseptal selülit, orbital selülit ve menenjit ile komplike olabilmektedir (4-6). Gerek sulanma ve çapaklanmanın deprivasyon etkisiyle, gerek KNLKT olan çocuklardaki artmış hipermetropi görülme sıklığı sebebiyle, ambliyopi riski de taşımaktadır $(7,8)$.

Nazolakrimal kanal doğumda henüz olgunlaşmamıştır. Tıkanıklığın en sık nedeni Hasner valvinde veya nazolakrimal kanalın meatus nazi inferiora açıldığı distal uçta gelişen membranöz tıkanıklıktır $(9,10)$. Belirtiler genellikle yaşamın ilk birkaç haftasında ortaya çıkar $(1,10)$. Yaşamın ilk aylarında genellikle kendiliğinden açılan bu tıkanıklık, gerektiğinde hidrostatik basıncı artıracak şekilde yapılan masaj ile, olguların \%96 kadarında, yaşamın ilk yılında açılabilmektedir (11-14).

Bu çalışmanın amacı son yıllarda artan sezaryen doğum (SD) oranlarının, yaşamın ilk yıllarında sık hastane ziyareti, takip ve tedavi gerektiren, ambliyopi riski de taşıyan KNLKT sıklığıyla ilişkisini değerlendirmektir.

\section{GEREÇ ve YÖNTEMLER}

Mart 2014- Şubat 2017 tarihleri arasında 1 yaş altında epifora ve/veya çapaklanma şikayeti ile polikliniğe başvuran hastalar nazolakrimal kanal tıkanıkıı̆ı açısından değerlendirildi. Çalışma için Ankara Şehir Hastanesi 1 Nolu Klinik Araştırmalar Etik Kurulu'ndan E1-21-2042/22.09.2021 numaralı onay alındı ve çalışma Helsinki Deklarasyonu prensiplerine uygun olarak yapıldı.

Şikayetlerin doğumun 1. ayından sonra başlamış olması, rekürren karakterde olması, kese bölgesine bastırlınca sekresyon gelmesi bulgularıyla konjenital dakriyositenozdan şüphelenilmiş ve tanıyı kesinleştirmek için fluoresein boya kaybolma testi yapılarak pozitif sonuçlanan hastalar çalışmaya dahil edilmiştir. Hasta grubunu zamanında doğan (>38 hafta), normal gelişim gösteren, KNLKT dışında sağlık problemi olmayan bebekler oluşturmaktaydı. Ayrıca preterm doğan, yenidoğan yoğun bakım ihtiyacı olan, ek hastalığı olan hastalar çalışma dışı bırakıldı. Çalışmaya dahil edilen hastaların yaş, cinsiyet, lateralite ve doğum şekli bilgileri takip dosyalarından elde edildi.

Verilerin analizi SPSS version 20 programı ile yapıldı. SD ile normal vajinal yolla doğum (NVD) arasında tanımlayıcı ve sayısal parametrelerin karşılaştırımasında Mann-Whitney U testi kullanıldı. Çalışmaya 62 hastanın 75 gözü dahil edildi. Ancak aynı bireyin iki gözü arası korelasyondan kaynaklanabilecek istatistiksel hata riski nedeniyle, gruplar arası analizler 62 hasta üzerinden yapıldı. Testlerin değerlendirilmesinde "p" değerinin 0.05' den küçük olması ( $p<0.05$ ) istatistiksel olarak anlamlı kabul edildi.

\section{BULGULAR}

Çalışmaya dahil edilen 62 hastanın 35'i (\%56.5) erkek, 27 'si (\%43.5) kızdı. Doğum şekli 37 hastada (\%59.7) NVD iken 25 hastada (\%40.3) SD'di. Çalışmamızda doğum şeklinin NVD ya da SD olması ile KNLKT görülme sıklığı arasında ilişki saptanmadı $(p<0.128)$.

Toplam 62 hastanın 75 gözüne KNLKT tanısı kondu. Tıkanıklık hastaların 30'unda (\%48.4) sağda, 19'unda (\%30.6) solda ve 13'ünde (\%21) bilateraldi. Hastane başvuru yaşı ortalaması $5.5 \pm 4.6$ aydı (Tablo I).

NVD grubunda hastaneye başvuru yaşı $5.1 \pm 4.1$ ay iken SD grubunda 6.2 \pm 5.5 aydı ve iki grup arasında hastaneye başvuru yaşı istatistiksel olarak anlamlı farklılık göstermemekteydi $(p=0.501)$. NVD grubunda KNLKT hastaların 20'sinde (\%54.1) sağ gözde, 8'inde (\%21.6) sol gözde ve 9'unda (\%24.3) her iki gözde iken SD olan grupta hastaların 10'unda (\%40) sağ gözde, 11 'inde (\%44) sol gözde ve 4'ünde (\%16) her iki gözdeydi ve gruplar arasındaki KNLKT lateralitesindeki farkllık istatistiksel olarak anlamlı değildi ( $\mathrm{p}=0.624)$. NVD grubunda hastaların 17'si (\%45.9) erkek iken SD grubunda hastaların 18'i (\%72) erkekti ve gruplar arasındaki cinsiyet farklı̆̆ı istatistiksel olarak anlamlıydı $(p=0.044)$ (Tablo II).

2014-2016 yılları arasında Türkiye'deki sezaryen doğum oranı \%38'di ve çalışmamızdaki SD oranı ise \%40.2 bulundu. Çalışmamızdaki SD oranını Türkiye'deki SD oranı ile karşılaştırmak için kullanılan binomial test ile yapılan istatistiksel analizde, çalışmamızdaki SD oranı Türkiye'deki SD oranı ile benzer bulundu ( $p=0.399)$ (Şekil 1).

\section{Tablo I: Hastaların demografik ve klinik özellikleri.}

\begin{tabular}{|c|c|}
\hline \multicolumn{2}{|l|}{ Parametre } \\
\hline \multicolumn{2}{|l|}{ Cinsiyet $^{\star}$} \\
\hline $\mathrm{KIZ}$ & $27(43.5)$ \\
\hline Erkek & $35(56.5)$ \\
\hline Hastane başvuru yaşı (ay, ort_SS) & $5.5 \pm 4.6$ \\
\hline \multicolumn{2}{|l|}{ Doğum şekli* } \\
\hline NVD & $37(59.7)$ \\
\hline SD & 25 (40.3) \\
\hline \multicolumn{2}{|l|}{ Lateralite* } \\
\hline Sağ & $30(48.4)$ \\
\hline Sol & 19 (30.6) \\
\hline Bilateral & $13(21)$ \\
\hline
\end{tabular}

NVD: Normal vajinal yolla doğum, SD: sezaryen doğum, * $n(\%)$ 


\begin{tabular}{|c|c|c|c|}
\hline & NVD n (\%) & SD n (\%) & p \\
\hline Sayı & $37(59.8)$ & 25 (40.2) & 0.128 \\
\hline $\begin{array}{l}\text { Hastane başvuru yaşı } \\
\text { (ay, ort } \pm S S \text { ) }\end{array}$ & $5.1 \pm 4.1$ & $6.2 \pm 5.5$ & 0.501 \\
\hline Cinsiyet (n, K/E) & $\begin{array}{c}20 / 17 \\
(54.1 / 45.9)\end{array}$ & $7 / 18$ & $0.044^{*}$ \\
\hline $\begin{array}{l}\text { Lateralite } \\
\text { Sağ } \\
\text { Sol } \\
\text { Bilateral }\end{array}$ & $\begin{array}{r}20(54.1) \\
8(21.6) \\
9(24.3)\end{array}$ & $\begin{array}{r}10(40) \\
11(44) \\
4(16)\end{array}$ & 0.624 \\
\hline
\end{tabular}

E: Erkek, K: KIz, NVD: Normal vajinal yolla doğum, SD: Sezaryen doğum



Şekil 1: 2014-2016 Türkiye doğum verileri ile çalışma grubunun karşılaştııılması.

NVYD: Normal vajinal yolla doğum

\section{TARTIŞMA}

Konjenital nazolakrimal kanal tıkanıklı̆ının bilinen risk faktörleri, prematürite, kraniofasial hastalıklar, Down Sendromu, maternal enfeksiyonlar, genetik yatkınlıktır $(2,3,15)$. Ancak son yıllarda artan SD oranları göz önünde bulundurulduğunda doğum şeklinin KNLKT etyopatogenezinde rol alabileceği öngörülmüş ve yapılan çalışmalarda farklı sonuçlar bildirilmiş̧ir. Bazı çalışmalarda SD ile KNLKT arasında ilişki bulunurken, bazı çalışmalarda sadece ilk doğumun SD olması ya da kompleks doğumların KNLKT ile iliş̧kili olduğu bildirilmiştir (16-21).

Spaniol ve ark. (19) yaptığı bir çalışmada ilk doğumun SD olmasının KNLKT için artmış bir risk faktörü olduğunu göstermişlerdir. Alakuş ve ark. (20) ilk doğumun SD olmasının ve ailede KNLKT hikayesi olmasının KNLKT etyopatogenezinde önemli bir risk faktörü olabileceğini bildirmişlerdir. Bu iki çalışmada da ilk ve tekrarlayan SD'ler ayrı ayrı olarak incelenmiş ve ilk doğum SD olanlarda KNLKT görülme sıklığı artmış olarak bulunmuştur. Literatürde yapılan çalışmalar göz önüne alındığında SD ile KNLKT görülme sıklığı arasındaki ilişkiyi araştıırken, yalnızca ilk doğumları değil, tüm doğumların dikkate alınması gerektiği vurgulanmaktadır. Ancak bizim çalışmamızda bu ayrımın yapılmamış olması çalışmamızın bir kısıtlıı̆̆ıdır.

Illk doğum NVD olanlarda ilk doğum SD olanlara kıyasla KNLKT görülme sıklığının daha az bulunduğu çalışmalarda doğum sırasındaki yüksek dış basınç ve kollajenolitik aktivitenin Hasner membranında açımaya neden olabileceği ileri sürülmüştür $(16,17)$. Ancak bu çalışmalara dahil edilen hasta sayılarının azlığı ve bu çalıșmalarda kendiliğinden rezolüsyon oranlarının düşük bildirilmiş olması da çalışmaya dahil edilme kriterlerinde güvenilirliğin sağlanamamış olabileceği fikrini desteklemektedir.

KNLKT tespit ettiğimiz hastalarda SD oranı \%40.2 iken aynı dönemde Türkiye'de SD oranı \%38'di. Çalıșmamızda SD oranı Türkiye ortalamasından fazla olsa da bu farklllik istatistiksel olarak anlamlı değildi. Daha geniş hasta sayılarını içeren çalışmalarla KNLKT etyopatogenezinde doğum şeklinin KNLKT ile ilişkisi aydınlatılabilecektir.

Yaptı̆̆ımız çalışmada doğum şeklinin NVD ya da SD olmasının KNLKT görülme sıklğı arasında ilişki tespit edilmedi. Bu yönü ile Yıldız ve ark.'nın (22) ülkemizde yaptığı 40 olguyu içeren çalışmada ve Amerika'da yapılmış 17.713 yenidoğanın dahil edildiği 1998 KNLKT tanısı ile takip edilmiş on yıllık verileri içeren geniş kohort çalışmasında SD oranı ile KNLKT görülme sıklğı arasında bir ilişki saptanmamış olması bizim çalışma sonuçlarımızla benzerlik göstermektedir (2).

Literatürde KNLKT çoğunlukla tek taraflı görünürken olguların \%20'sinde iki taraflı olduğu bildirilmiştir. Bizim çalışmamızda da hastaların \%21'inde KNLKT iki taraflıydı ve literatürle uyumluydu (23). Çalışmamızda SD ile doğan erkek bebeklerde kız bebeklere göre KNLKT daha sık tespit edilmiştir. Ancak literatürde bu sonuçla uyumlu herhangi bir veriye rastlanmamıştır. Çalışmaya dahil edilen hasta sayısının azlığı bu sonucun anlamlılı̆ını düşürmekle birlikte daha geniş hasta sayılarının dahil edileceği çalışmalara intiyaç vardır.

Sonuç olarak; bizim çalışmamızda doğum şekli ile KNLKT görülme sıklığı arasında ilişki tespit edilmemiştir. KNLKT çok faktörlü etyopatogeneze sahiptir ve doğum şeklinin bu etyopatogenezdeki rolü tartışmalı olarak devam etmektedir.

\section{KAYNAKLAR}

1. MacEwen CJ, Young JD. Epiphora during the first year of life. Eye (Lond) 1991;5:596-600.

2. Sathiamoorthi S, Frank RD, Mohney BG. Incidence and clinical characteristics of congenital nasolacrimal duct obstruction. $\mathrm{Br} \mathrm{J}$ Ophthalmol 2019103:527-9.

3. Aldahash FD, Al-Mubarak MF, Alenizi SH, Al-Faky YH. Risk factors for developing congenital nasolacrimal duct obstruction. Saudi J Ophthalmol 2014;28:58-60.

4. Kashkouli MB, Sadeghipour A, Kaghazkanani R, Bayat A, Pakdel F, Aghai GH. Pathogenesis of primary acquired nasolacrimal duct obstruction. Orbit 2010;29:11-5. 
5. Bekmez S, Eriș E, Altan EV, Dursun V. The Role of Bacterial Etiology in the Tear Duct Infections Secondary to Congenital Nasolacrimal Duct Obstructions. J Craniofac Surg 2019;30:2214-6.

6. Ali MJ. Pediatric Acute Dacryocystitis. Ophthalmic Plast Reconstr Surg 2015;31:341-7.

7. Matta NS, Singman EL, Silbert DI. Prevalence of amblyopia risk factors in congenital nasolacrimal duct obstruction. J AAPOS 2010;14:386-8.

8. Eshraghi B, Akbari MR, Fard MA, Shahsanaei A, Assari R, Mirmohammadsadeghi $A$. The prevalence of amblyogenic factors in children with persistent congenital nasolacrimal duct obstruction. Graefes Arch Clin Exp Ophthalmol 2014;252:184752.

9. Cassady JV. Developmental anatomy of nasolacrimal duct. AMA Arch Ophthalmol 1952;47:141-58.

10. Young JD, MacEwen CJ. Managing congenital lacrimal obstruction in general practice. BMJ 1997;315:293-6.

11. Petersen RA, Robb RM. The natural course of congenital obstruction of the nasolacrimal duct. $J$ Pediatr Ophthalmol Strabismus 1978;15:246-50.

12. Pediatric Eye Disease Investigator Group. Resolution of congenital nasolacrimal duct obstruction with nonsurgical management. Arch Ophthalmol 2012;130:730-4.

13. Świerczyńska M, Tobiczyk E, Rodak P, Barchanowska D, Filipek E. Success rates of probing for congenital nasolacrimal duct obstruction at various ages. BMC Ophthalmol 2020;20:403.

14. MacEwen CJ, Young JD, Barras CW, Ram B, White PS. Value of nasal endoscopy and probing in the diagnosis and management of children with congenital epiphora. Br J Ophthalmol 2001;85:3148.
15. Lorena SH, Silva JA, Scarpi MJ. Congenital nasolacrimal duct obstruction in premature children. J Pediatr Ophthalmol Strabismus 2013;50:239-44.

16. Tavakoli M, Osigian CJ, Saksiriwutto P, Reyes-Capo DP, Choi CJ, Vanner EA, et al. Association between congenital nasolacrimal duct obstruction and mode of delivery at birth. J AAPOS 2018;22:381-5.

17. Kuhli-Hattenbach C, Lüchtenberg M, Hofmann C, Kohnen T. Erhöhte Prävalenz konnataler Tränenwegsstenosen nach Sectio caesarea [Increased prevalence of congenital dacryostenosis following cesarean section]. Ophthalmologe 2016;113:675-83.

18. Dolar Bilge A. Mode of delivery, birth weight and the incidence of congenital nasolacrimal duct obstruction. Int $\mathrm{J}$ Ophthalmol 2019;12:1134-8.

19. Spaniol K, Stupp T, Melcher C, Beheiri N, Eter N, Prokosch V. Association between congenital nasolacrimal duct obstruction and delivery by cesarean section. Am J Perinatol 2015;32:271-6.

20. Alakus MF, Dag U, Balsak S, Erdem S, Oncul H, Akgol S, et al. Is there an association between congenital nasolacrimal duct obstruction and cesarean delivery? Eur J Ophthalmol 2020;30:1228-31.

21. Palo M, Gupta S, Naik MN, Ali MJ. Congenital Nasolacrimal Duct Obstruction and Its Association With the Mode of Birth. J Pediatr Ophthalmol Strabismus 2018;55:266-8.

22. Yildiz A. Congenital nasolacrimal duct obstruction: caesarean section vs. vaginal delivery. Med Glas (Zenica) 2018;15:164-7.

23. Olitsky SE. Update on congenital nasolacrimal duct obstruction. Int Ophthalmol Clin 2014;54:1-7. 